\title{
The Scottish Health Advisory Service visit
}

\section{A model for training in psychiatry}

\author{
Shiona Macdonald
}

The Scottish Health Advisory Service (SHAS) was established in 1970 to provide information to the Secretary of State for Scotland and the Health Board on the management and running of hospitals for the elderly and for patients with mental illness and learning disability. The Health Advisory Service serves a similar purpose in England and Wales. The purpose of SHAS is to promote high standards of health care for these patients. The SHAS achieves this in different ways, but one of their main functions is to visit the hospitals regularly to assess the quality and effectiveness of the service.

During a SHAS visit, four members of SHAS will visit wards, departments and community facilities and interview management and staff to obtain a comprehensive view of the service. At the end of the visit, a final SHAS report with recommendations is published and submitted to the Secretary of State and the Chief Executive of the National Health Service in Scotland. It was decided to use this model of a SHAS visit as a training experience for junior staff, including medical staff, to look at care provided within Argyll and Bute Hospital, Lochgilphead.

The Argyll and Bute Hospital provides psychiatric in-patient services to the populations of Argyll and Bute district and, at the time of our visit, Dumbarton district. The hospital has two acute assessment wards, an intensive care unit, an alcohol treatment unit, a rehabilitation unit and four wards for long-stay elderly patients. Community services were not within the remit of our visit. Other areas visited within the hospital included the occupational therapy department, the electroconvulsive therapy suite, social work department, the laundry and the patients' canteen. In the model of the SHAS visit, the above areas were visited over a two-day period by a team of six junior staff to examine many different aspects of patient care, for example, ward fabric, record-keeping, staff morale, quality of food, consultant availability, etc.

During the two-day visit the Management Advisory Group (MAG), who are responsible for the day to day management of the hospital, were also interviewed about their achievements, concerns and plans for the future of the hospital. Like SHAS, at the end of this visit, a report of the observations made during the visit was compiled. This report was then discussed at a joint meeting between MAG and the junior staff involved. From this meeting arose 39 points of concern to be considered further by the MAG to help improve patient care.

The model of the SHAS visit used at the Argyll and Bute Hospital was different in many ways to the real thing. It was used primarily as a training experience for junior staff. The team was comprised of two senior house officers, a junior social worker, two E-grade staff nurses and a secretary. This contrasts sharply with the usual glut of experience, seniority and insight that the SHAS demands from its members. This inexperience made tackling management issues of policy. strategy and planning difficult, but the grassroots background meant that they paid attention to the smaller details. Unlike the SHAS, the team were insiders in the service which inevitably affected objectivity. Fortunately, staff took the visit seriously although maintaining a healthy scepticism about the team's ability to effect change. While SHAS has to deal with the political repercussions from their reports, the team had to deal with the personal repercussions of commenting on colleagues and superiors.

Using this model of the SHAS visit not only provided a training opportunity but also yielded useful information about the service. Despite the obvious lack of power of the mock-SHAS team. the MAG took the findings seriously and put them as standing items on their agenda to follow through. A review of these standing items one year later revealed that of the 39 items identified as needing improvement, 18 had been satisfactorily resolved, 10 were actively under review and the remaining 11 were part of longer term reviews of the service. Of the 18 items resolved, the following are examples:

(a) Two of the units in the hospital could not be accessed via the house key, thereby 
making entry in an emergency difficult. The locks were changed to house keys.

(b) The Medical Records Office was left unlocked most of the day, potentially allowing access for unauthorised persons. This was rectified by the office being locked at all times.

(c) The new cafeteria had no non-smoking areas. There is now no smoking allowed at all in the cafeteria.

(d) There was a general lack of in-house training for nursing staff. A Nursing Academic Programme was commenced nine months later.

(e) The crisis loan system for patients being admitted to hospital did not work out-ofhours and at the weekends. A float is now held in the acute ward for this purpose.

(f) The consultant on-call now carries a pager to enable easier contact with him.

In our present climate, it is also important to note that this exercise was inexpensive - the only real cost was the time used in planning and executing the visit by the junior staff involved.

The SHAS visit model was a valuable training experience for all those involved. Basic trainees are strongly encouraged to perform audit which involves focusing in on specific areas of a service. Rarely, however, is there an opportunity to get a feel for the 'bigger picture'. During this exercise, areas of the hospital that were previously unknown were visited and allowed discussion with staff to hear their views of the service. There was face to face contact with previously unknown managers and patients in all the wards, who were interviewed to find out what life was like outside the ward round.
It gave the opportunity to develop essential skills required for career development research, planning and organisation were essential prior to the visit. Diplomacy, interrogation and stamina during the visit and analysis and collation of information afterwards. This information then had to be presented in a coherent and convincing way to persuade the managerial audience of its validity.

Finally, working as a team allowed the opportunity to explore leadership and team-building issues both of which were important to success.

The SHAS visit model could easily be reproduced in other hospitals to their and their trainees' advantage. Support from the hospital management for this project was vital. This filtered downline to the wards and departments and helped give the mock-SHAS visit credibility. This support would be essential to the success of such a venture elsewhere.

\section{Acknowledgements}

I would like to thank Dr A. V. P. Mackay for the original idea and his encouragement throughout and Dr Donald Rankine, then Medical Director of SHAS, for his helpful advice. The other team members were Joanne Crawford, Jane Garrity, Dr Stephen Gurling, Geraldine Hannan and Avril Lockhart.

Dr Shiona Macdonald, Specialist Registrar in General Adult Psychiatry, Hartfield House Resource Centre, 1 Racecourse View, Ayr KA7 2TS 